University of Nebraska - Lincoln

DigitalCommons@University of Nebraska - Lincoln

To Improve the Academy

Professional and Organizational Development

Network in Higher Education

1998

Implications of the Nature of "Expertise" for Teaching and Faculty
Development

Richard G. Tiberius

Ronald A. Smith

Zohar Waisman

Follow this and additional works at: https://digitalcommons.unl.edu/podimproveacad

Part of the Higher Education Administration Commons

Tiberius, Richard G.; Smith, Ronald A.; and Waisman, Zohar, "Implications of the Nature of "Expertise" for Teaching and Faculty Development" (1998). To Improve the Academy. 419.

https://digitalcommons.unl.edu/podimproveacad/419

This Article is brought to you for free and open access by the Professional and Organizational Development Network in Higher Education at DigitalCommons@University of Nebraska - Lincoln. It has been accepted for inclusion in To Improve the Academy by an authorized administrator of DigitalCommons@University of Nebraska - Lincoln. 
Tiberius, R. G., Smith, R. A., \& Waisman, Z. (1998). Implications of the nature of "expertise" for teaching and faculty development. In M. Kaplan (Ed.), To Improve the Academy, Vol. 17, (pp. 123-138). Stillwater, OK: New Forums Press and the Professional and Organizational Development Network in Higher Education. Key Words: faculty development, motivation, personal development, teaching skills, theories.

\section{Implications of the Nature of "Expertise" for Teaching and Faculty Development}

\section{Richard G. Tiberius}

University of Toronto

\section{Ronald A. Smith}

Concordia University

\section{Zohar Waisman}

University of Toronto

Over the last two decades cognitive theorists have learned that the development of expertise goes beyond the accumulation of knowledge and skills: expertise includes the development of pattern recognition and learned procedures that enable practitioners to deal with problems effortlessly or intuitively. Even more recently, theorists are distinguishing experts from experienced non-experts by how they use the bonus time and energy gained from solving problems intuitively. Experts invest it in tackling problems that increase their expertise rather than reduce problems to previously learned routines. Some implications of these different views of expertise for teaching and faculty development are discussed. 
How do teachers or educational developers become experts? Indeed, how does anyone become an expert? There is an increasing interest in this question by both cognitive scientists and educators. It is an important question because the word "expert" has positive value in our society. Built into the word "expert" is the idea of superior effectiveness. In a culture that is completely dependent on high performance, expertise justifies higher salaries and respect. Students want to graduate from our institutions into the world of work with expertise in some area of activity or profession. Teachers need to understand the nature of the expertise that their students want to acquire. Teachers should also be interested in the expertise of teaching, which is necessary for them to be effective in helping their students to become experts. And faculty developers should be interested in acquiring the expertise necessary for teaching, as well as the expertise required to help faculty members.

As important as it is, expertise is not an easy goal to pursue these days because the concept has become a moving target. Over the last few decades systematic inquiry into the nature of expertise has changed our understanding of the concept. In this paper we will argue that the concept of "expertise" is growing more sophisticated as theorists refine the distinction between ordinary learning and expertise. Specifically, we will describe two recent revolutions in the meaning of "expertise." Then we will speculate, and invite the reader to speculate, concerning the implications of these definitions for teaching and for faculty development.

The bar graph (See Figure 1) illustrates how the definition of expertise has grown, by accretion. The bedrock, widely accepted view is that expertise is based on special knowledge or skills. For generations our institutions and teaching methods have been in tune with this view. We have produced experts by transmitting information (Barr and Tagg, 1997; Tiberius, 1970). The better learners were those who memorized more material and recalled more of it on exams; the better teachers transmitted more information to their students; and the better faculty developers had larger repertoires of strategies to suggest to teachers.

Current theory on expertise does not challenge the central role of information in expertise, but it distinguishes high performers from 
others in the way they deal with new issues rather than just the amount of knowledge they have (Dreyfus and Dreyfus, 1986; Anderson, 1985). After a great deal of experience, the way people solve problems appears to change. They begin to deal with issues by second nature, with hardly any thought or effort. Furthermore, this increased efficiency is not gained at the expense of effectiveness. They become highly successful as they become more efficient. The secret is that they begin to recognize certain recurring patterns in their work, and they develop learned procedures to deal with these.

This kind of efficient, intuitive, problem solving adds an important new dimension to the old concept of "expertise as an accumulation of knowledge." The new view is gaining popular appeal among educators because it fits with everyday experience. As experienced drivers, we can negotiate traffic while talking and tuning the radio with hardly any thought given to driving. This view of expertise, depicted as the second bar in our figure, has become the most popular view of expertise among cognitive theorists.

One of us (Zohar) had an experience that provides a striking illustration of this kind of expertise. On a recent flight overseas Zohar, a resident in the Department of Psychiatry, was startled out of his daydream by one of the most dreaded experiences in a resident's life, the steward asking over the intercom, "Is there a physician on the plane?"One of the passengers had chest pain. Zohar's own heart began racing. He proceeded systematically taking a complete medical history while the thought raced through his mind: "What if this is a heart attack? Should I ask them to land the plane at the nearest airport? I will need an ECG and cardiac enzymes." After a few minutes another passenger, whom Zohar recognized as a professor emeritus of cardiology, came over to the patient. The professor asked the patient three brief questions pertaining to the nature and the location of the pain, then turned to Zohar and quietly told him that the patient's problem was more in Zohar's realm than in his - that the origin of the pain was not cardiac and was most likely due to a panic attack.

Both the cardiologist and Zohar had sufficient knowledge to manage the patient according to the widely accepted model. However, they differed in their ability to use pattern recognition to solve cardiac problems. As a psychiatry resident who was not used to dealing with 
patients who present with chest pain, Zohar attempted to fit the patient's symptoms into a rigidly applied flow chart. He needed more time and questions to do this. In other words, he had to use a deliberate problem-solving technique. The cardiologist was able to skip the process and fit the case into a known pattern.

The same contrasts characterize novice and expert teachers and developers. Novices are tied to deliberate problem solving and stepwise rules while experts can solve problems using efficient holistic methods. New teachers are often rigidly focused on their notes. They cover the material as if they were dictating. When asked a question that is out of sequence they might likely answer with "I'll be getting to that later." Experienced teachers, in contrast, have organized their information into curriculum scripts (Putnam, 1987; Shulman, 1987). Curriculum scripts are little packages for teaching particular concepts. They include sets of learning objectives, teaching methods (such as examples and questions), and knowledge of the students' most likely misconceptions. Scripts enhance teachers' efficiency because they enable teachers to teach in response to students' questions. The use of scripts is especially powerful in interactive teaching situations such as small group and one-to-one teaching (See Irby, 1992, 1994). But scripts can give experts an advantage over novices even in the traditional lecture format. The highly experienced teacher may ask a few questions or pause to gather information that enables her or him to sense whether to use another example or to move on. The flexibility that allows interactive teaching is the implication of expertise as pattern recognition and learned procedures.

Another implication of this intuitive aspect of expertise, as the Dreyfuses (1986) propound it, is more disquieting for educators. Let's consider separately expertise in the subject matter and expertise in teaching skills. We all know that expertise in the subject does not necessarily make a good teacher. Their theory would predict that experience may actually be a handicap. Experienced teachers who have achieved the kind of smooth performance characterized by instant recognition of problem situations and efficient actions, without deliberation, are clearly expert in the sense that Dreyfus and Dreyfus use the term. But such teachers tend to make decisions without being aware of the rules or without having rules. They make decisions on 
the basis of subtle, contextual features of the situation, features that are unavailable to the novice. Such teachers often have difficulty explaining to students their thoughts or actions that constitute expert practice.

A recent educational conference in the Canadian Rocky Mountains provided an example of the expert's difficulty in teaching. When a colleague, Leon, heard that one of us (Richard) was a tree enthusiast, Leon invited him on a hike to help the group identify the trees. Time and again as they ascended the switchbacks Leon asked Richard to distinguish a fir from a spruce. Finally, he said, "Richard, I'm not getting it. Do you have some kind of rule that I could use?" After an embarrassing delay, Richard managed to recall the rules that he had learned when he first began to study trees. With confidence he directed Leon to pluck a needle off of each of two trees and try to roll them between his fingers. Leon was delighted. One of them would roll between the fingers and the other would not because its needles were too flat. But which was the spruce? Richard just couldn't remember! He had not used the needle-rolling test for years. He could distinguish the trees at 50 yards based on relative differences in shape, color, and texture, all of which are very subtle features for the novice. Teachers who are experts in any subject tend to make judgments that are different from those used by novices. The experienced teacher integrates many features, some of which are quite subtle, holistic, and unavailable to those with less experience.

Fortunately, Richard remembered another differential-spruce cones hang down while fir cones stand up. Leon found this new rule enormously satisfying. Drawing presumably on skills learned during his medical student days, he coined a mnemonic on the spot: "If your cone hangs down, spruce up," just as his medical students have. Experts have organized their knowledge in a form that makes it highly accessible for them to use in solving problems in their fields. But the underlying rules and principles are sometimes difficult for them to recall, just as it was difficult for Richard to recall the decision rule about the needles. Teachers who are experts in their fields need to learn the perspective of novices in order to help them. Teachers must be able to flip back into the problem-solving mode of their learners in order to connect with them. Interaction with learners is one of the best means 
of ensuring that teachers acquire and maintain an understanding of the framework of their learners. Thus the contemporary model of teaching and learning as a dialogue is a helpful perspective for experts who easily lose touch with their learners.

Expertise in teaching follows the same pattern as expertise in the subject matter. The expert teacher in one setting may not be expert in another setting. Clinical teachers, for example, have their scripts tied to patient problems (Irby, 1992), and math teachers have scripts that are unique to math (Putnam, 1987). Teaching too is context specific. The two of us who are developers (Ron and Richard) did not have to look hard to find an example of this. The one we had in common was the practice teaching session in which a novice teacher gives a superb lecture-complete with moving computer graphics, a formal question period, lots of movement around the front of the room, and impressive volume - to a group of six colleagues! In the feedback session that followed his presentation, we asked him if his colleagues were supposed to pretend they were a larger audience. "No," he said, "I'm struggling to reshape my talk to fit small groups." His predicament would not seem strange to most developers, although it may be puzzling to teachers. What may seem strange, even to developers, is that the other participants in the class, who were quite good at small group presentations, nevertheless had little to contribute in aid of their colleague. They had their scripts but were not aware of them.

Nor are developers exempt from the downside of the "automatic" or "intuitive" aspect of their expertise. Ron and Richard both train new developers. They struggle against the tendency of the novice to solve every problem with a workshop. Unfortunately, there are some experienced developers in the field who run excellent workshops but have only this one arrow in their quiver.

Recently a third layer has been added to the growing structure of "expertise." Bereiter and Scardamalia (1993) argue that not all experience leads to expertise. The kind of efficient, intuitive approach to problems that we have been discussing happens to everyone after a sufficient amount of experience, whether they are successful at what they do or not. The problem with previous research on expertise, they argue, is that researchers have compared expert performers with novices. They argue that studies should compare expert performers to 
experienced non-experts, that is, those who, despite having had lots of experience, do not achieve expert performance. What previous researchers failed to do is to consider the possibility that there exists a group of learners who fail to reach proficiency despite having had lots of experience. To continue with the driving example used by Bereiter and Scardamalia, all of us pay less attention to our driving as we gain experience, but some of us become expert drivers while others become mindless menaces on the road.

Bereiter and Scardamalia argue that the true test of an expert goes beyond amount of knowledge or intuitive problem solving. The feature that really distinguishes experts from others is their approach to new problems. The pattern recognition and learned procedures that lead to intuitive problem solving are the beginning of this approach. Pattern recognition and learned procedures increase one's efficiency, resulting in a dividend in energy and time. The key to expert behavior is what the expert does with this bonus of time and energy. The expert invests it in what Bereiter and Scardamalia call progressive problem solving, that is, tackling problems that increase expertise rather than reducing problems to previously learned routines. (See Figure 1).

An example of someone who is expert in the first two senses but not in the third may make our point clearer. We have to go no further than a large hardware chain of stores. Richard asked the sales representative for help in finding a hook on which to hang his ladder. The sales person's face brightened. With a cheery smile he replied: "we don't have ladder hooks." Now why was this man so happy? Perhaps he was trained to be pleasant to customers. Not a chance. We are familiar with the store. The real reason is that he is an expert in the first two senses used in this paper but not in the third sense. He has a thorough knowledge of the inventory of the store and has developed smooth routines for handling customers. Indeed, he has a heuristic. It goes like this: If we have what the customer requests, I point him to the appropriate section, and he's out of my face. If we don't have what the customer requests, I say 'we don't have it,' and he's out of my face." The beauty of this heuristic is that the customer is out of his face in a few seconds no matter what the problem. He can handle all the problems of his job with a few simple procedures. To achieve this level of proficiency, he had to become expert in the first two senses that we 
are describing. He had to learn a lot of information about the location of goods in the store, and he had to have some heuristics for dealing with common situations. But he is not growing or increasing his expertise and not challenging his old routines and structures with new problems. In fact, he forces new problems into old structures rather than using them as occasions for new learning.

To find an expert in the third sense in which we are using it, Richard had to go down to the corner hardware store. The owner, who served Richard, also did not have a ladder hook, but hesitated when asked for one. This hesitation is a strong clue that reflection might be happening. Perhaps he was motivated to make a sale, but his approach was to attempt to solve the ladder hook problem, and it was not a typical one. He asked how large the ladder was. When he learned that it was 40 feet long he replied, "Oh dear, that's a very heavy ladder. I don't carry any of the aluminum brackets made especially for ladders, but I wouldn't trust them with such a heavy ladder. Would you consider a steel bracket? Let me show you how you can fix it to hold your ladder." He had never had a request for a ladder hook before, but he engaged the problem, explored it to see if there was a useful match between the customer's needs and his stock. As it turned out Richard did not buy the bracket that day because he is not at the expert stage in home repair. He was inflexibly looking for an official "ladder hook." He found one at a third store. The ladder bent it, and he returned to the corner store for steel brackets to support the ladder hook. Expertise in this third sense lies in an approach to one's work. The expert takes on new problems with the expectation that the challenge will increase his or her expertise. The non-expert strives to reduce new problems to previously learned routines.

What are the implications for teaching and faculty development of a conception of expertise as reflection and reinvestment in progressive problem solving? For one thing, the concept enables us to understand how experienced practitioners can easily fall into ruts. For another, it provides us with some understanding of the situations in which routines are valuable and some suggestions for avoiding them when they are not. Bereiter and Scardamalia (1993, p. 109) argue that experts, through the very process that enables them to become skillful (routinizing), may be deepening a rut that will eventually entrap them. 
They can become "deadwood," resistant to new ways of doing things, like the salesman in the large store.

Contemporary theorists of teacher development recognize that when experienced teachers become more efficient in carrying out their tasks they tend to shift their focus to new aspects of their environment (Pratt, 1989; Sherman et. al, 1987; Boice, 1992). New teachers focus mainly on content. With more experience they begin to focus on delivery, that is, teaching performance. Eventually, when both the content and the delivery become second nature, they begin to notice the social and personal aspects of their students. They become more interactive and responsive. This is the good news. Efficiency in one component of teaching provides extra time and energy that allows the teacher to move on toward mastery of another component.

But there are other teachers who continue to use the old notes, the old methods, while disengaging from the course and the class. The extra time and energy that they gain from having their teaching "organized" is invested in research. In some institutions these teachers are normative and supported by the institutional values. Such teachers illustrate Bereiter and Scardamalia's idea that expertise is not a static feature, to be achieved once and then abandoned, but a continual process over time. Expertise in teaching is an approach toward one's career.

We suspect that some educational developers, too, acquire highly skilled performances and then force fit new problems to their skills. We mentioned the developer who uses workshops all the time although some reflection might reveal that another method, such as individual consultation or micro-teaching, might be better matched to the problem. One of the most common problems of teaching, in our experience, is the kind of rigidity that fails to accommodate to the students, the subject, or the context.

Since we rarely view learners as expert in any sense of the word, we would not suspect that they too might be entrapped by their knowledge and routine procedures. Some research in progress (Waisman, et al., 1998) provides an example of such effects on learners. Zohar is teaching and studying third year medical students who are completely naíve with respect to psychiatry. He has found that his students have highly developed routines for dealing with personality 
disordered patients. At first Zohar found it strange that they had such routines. After all, undergraduate medical students are new to medicine. Then he realized that, although the phenomena of cardiology, like mitral valve prolapse, are new to medical students, manipulative bullying is not. Psychiatrists deal with issues that all of us have encountered many times in everyday life, although perhaps in less extreme forms. Medical students, therefore, have developed a kind of expertise, at least the knowledge and the routines, for handling difficult people. Unhappily, these routines are not useful therapeutically, although they appear to have survival value for the student. It is inappropriate to "get even" with a patient during an interview. Zohar has had to develop teaching methods that overcome the routines with which students begin his course.

But not everyone needs to be expert at everything. Routines can be useful. Many teachers are daunted at the prospect of learning how to teach for the rest of their professional lives. They settle into comfortable procedures that have worked for them in the past. Indeed, all of us do this with regard to most aspects of life. Who wants to reflect continually on taking out the garbage or brushing one's teeth? These are tasks we would rather do by routine, reserving our energy and attention for more important things. Certainly there are teachers for whom a non-reflective approach (non-expert in this third sense) to teaching is sufficient. Consider, for example, the visiting speaker who delivers a punchy, dramatic lecture on a specific topic, once a year. Although this lecturer may have stopped growing years ago, her or his performance may constitute an important contribution to the course. But in higher education, teaching can rarely be "canned." Academe especially is not organized enough to enable teaching specialization by matching teacher skills to tasks. * The naturally gifted orator must also develop curriculum and teach small groups and supervise theses. The current situation requires a high level of expertise in the sense that Bereiter and Scardamalia mean it: reinvesting time and energy and continually learning to meet new challenges from changes in curricu-

\footnotetext{
*The idea of matching teacher talents with teaching tasks is currently being pursued in a forthcoming New Directions in Teaching and Learning volume edited by James Bess.
} 
lum, students, or subject matter. Indeed, as Ron Smith (1997) argued in "Making Teaching Count in Canadian Higher Education," too many in higher education do not recognize that expertise of any sort is required in teaching beyond an advanced degree in the subject. He encourages teachers to view teaching as scholarly work, as difficult and creative work, as requiring our best efforts and as worthy of high regard in the academy. We need to move beyond pedagogical solitude towards teaching as community property (Shulman, 1987), the community of scholars, or experts in teaching.

Those who wish to become professional teachers must prevent falling into ruts by engagement in what Bereiter and Scardamalia (1993, p. 111) call progressive problem solving. They need to think of their automated skills as building blocks of new skills that are not automated. For example, the experienced chess player acquires many learned patterns and procedures, but for the expert they do not become stereotyped, predictable, moves that restrict thinking. Instead, they are used as building blocks for increasingly sophisticated analyses. The experienced teacher recognizes many familiar patterns in the classroom or in interaction with students or in grading papers, but resists responding in stereotypic fashion. Instead he or she continually redefines the classroom situation and reinterprets the individual student. The teacher learns about the student as the student is learning about the material (Freire, 1973).

Developers can certainly not afford to rely on routines. We cannot imagine there ever being a sufficient number of developers in any institution to enable a cooperative arrangement to enable each developer to carry out routine procedures. Developers must continually reinvest their energy to meet new challenges because their world is always changing.

How can teachers and developers become more expert in this third aspect of the concept? We have drawn from Bereiter and Scardamalia's (1993) suggestions for building an environment that would encourage reinvestment and progressive problem solving. And we have added to these our own speculations and some that grew out of our workshop at POD in October, 1997, on the topic of expertise. We invite you to consider the implications of the concept of expertise for your own setting. 
1. Consider using Classroom Research, as designed by Angelo and Cross (1993). Teachers and faculty developers can use these methods on their own to investigate the impact of their own actions on their students and clients in specific settings. Faculty developers should try to engage faculty in becoming reflective practitioners and classroom researchers. Developers should do the same with regard to their own performance. In short, discourse about teaching should be taken seriously, and it should be scholarly.

2. Consider organizing pedagogical colloquiums that can develop cultures beyond pedagogical solitude. These could become part of regular departmental life. Of course, many developers work alone, but we could create electronic colloquia.

3. Consider arranging reflective practica, as suggested by Donald Schön (1987) both for faculty members and for developers. These could provide opportunities for practitioners to share their thinking about real problems. They are now used in teacher education. Case study is at the heart of such arrangements. The key is to require students or teachers to develop "explanations" in addition to solving problems. Teachers should encourage students to develop their own theories, to account for facts, and to criticize their own and one another's theories by confronting them with facts. Developers should encourage teachers to develop their own theories of teaching, to account for the feedback they receive about their teaching, and then to move toward designing new actions.

4. Remember that dossiers can be useful tools for both teachers and developers, not only for assessment, but for reflection and growth as well. They encourage people to think deeply about their work and to think of their work with a view toward learning from colleagues.

5. Consider ways to connect with novices. Teachers might connect with novice students by using classroom assessment techniques such as reviewing student notes or interviewing students. Developers might connect with novice teachers in the same way. Teachers should encourage students to respond 
to one another's work and teach them how to do so in helpful, supportive ways. Developers should help teachers engage in classroom research and other scholarly (evidence-based) approaches to enhancing their teaching.

6. Engage in discussions aimed at changing the reward structure to reward or encourage the development of the various aspects of expertise as we have described it. The current system seems to encourage faculty to "satisfice" on teaching, to get it so that it is good enough, then move all their attention to research. In the same way that the pressures to cover the content prevent students from taking a "deep" approach to their learning and to studying for understanding, the pressure to publish may prevent faculty from taking the time to understand deeply the issues of teaching and learning. And what about developers? Do the pressures to keep those workshops filled, those newsletters going out, etc., keep us from thinking deeply and critically about our efforts to improve teaching and learning (Smith, 1995).

7. Although inquiry should be driven by learners' questions, it should not stop there. Teachers should encourage students to formulate questions at higher levels as inquiry proceeds. Developers should respond to the immediate needs of faculty but also encourage them to engage in alternative ways of thinking about their problem. Faculty should begin to see teaching improvement as a process of defining problems as well as solving them.

We have presented the argument that our view of expertise influences what we do to become experts, as well as how we try to help others develop their expertise. Teachers need to attend to their expertise in helping their students acquire the expertise they seek. Developers need to develop their own expertise in helping teachers become more expert as teachers. More work certainly needs to be done on the progression from novice, to experienced practitioner, to expert in each of these areas, but it will require at a minimum that we engage in progressive problem solving at the edge of our competence as learners, teachers, and developers. 


\section{References}

Angelo, T. A., \& Cross, K. P. (1993). Classroom assessment techniques: A handbook for college teachers (2nd edition). San Francisco: Jossey-Bass.

Anderson, J. R. (1985). Cognitive psychology and its implications. Cambridge, MA: Harvard University Press.

Barr, R. B., \& Tagg, J. (1995). From teaching to learning-A new paradigm for undergraduate education. Change, 27(6), 13-25.

Bereiter, C., \& Scardamalia, M. (1993). Surpassing ourselves: An inquiry into the nature and implications of expertise. Chicago, IL: Open Court.

Boice, R., (1992). The new faculty member. San Francisco: Jossey-Bass.

Dreyfus, H. L., \& Dreyfus, S. E. (1986). Mind over machine: The power of human intuition and expertise in the era of the computer. New York: The Free Press.

Freire, P. (1973). Education for critical consciousness. New York: Seabury Press.

Irby, D. M. (1992). How attending physicians make instructional decisions when conducting teaching rounds. Academic Medicine, 67(10), 630-638.

Irby, D. M. (1994). What clinical teachers in medicine need to know. Academic Medicine, 69(5), 333-342.

Pratt, D. D. (1989). Three stages of teacher competence: A developmental perspective. In E. R. Hayes (Ed.), Effective teaching styles. New Directions for Continuing Education, No 43. San Francisco: Jossey-Bass.

Putnam, R. T. (1987). Structuring and adjusting content for students: A study of live and simulated tutoring of addition. American Educational Research Journal, 24, 13-48.

Salthouse, T. A. (1991). Expertise as the circumvention of human processing limitations. In K. A. Ericsson \& J. Smith (Eds.), Toward a general theory of expertise: Prospects and limits (pp. 286-300). Cambridge, MA: Cambridge University Press.

Schön, D. A. (1987). Educating the reflective practitioner. San Francisco: Jossey-Bass.

Shulman, L. (1987). Knowledge and teaching: Foundations of the new reform. Harvard Educational Review, 57, 1-22.

Sherman, T. M., Armistead, L. P., Fowler, F., Barksdale, M. A., \& Reif, G. (1987). The quest for excellence in university teaching. Journal of Higher Education, 48(1), 66-84.

Smith, R. A. (1997). Making teaching count in Canadian higher education: Developing a national agenda. Teaching and Learning in Higher Education, 21, 1-10.

Smith, R. A. (1995). Reflecting critically on our efforts to improve university teaching. To Improve the Academy, 14, 5-25.

Tiberius, R. G. (1970). Metaphors underlying the improvement of teaching and learning. British Journal of Educational Technology, 17(2), 144-156.

Waisman, Z., Hodges, B., \& Tiberius, R. G. (1998). Teaching medical students despite their experience. Toronto, Canada: Department of Psychiatry Grand Rounds Presentation, University of Toronto. 


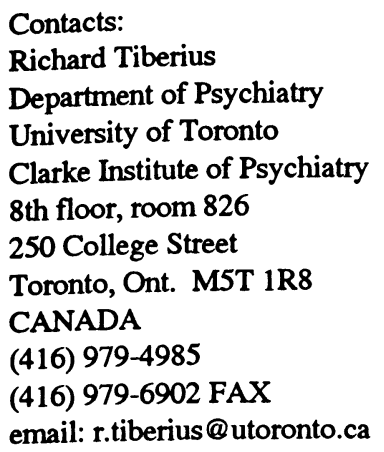

\section{Ron Smith}

Education Department

Concordia University

1455 deMaisonneuve Blvd. W.

Montreal, Quebec, H3G 1M8

\section{CANADA}

(514) 848-7338

email: rasmith@vax2.concordia.ca

Richard Tiberius is a professor in the Department of Psychiatry and at the Centre for Research in Education in the Faculty of Medicine at the University of Toronto, Canada. His main roles include collaboration with health science faculty on educational research projects, supervision of resident research, and various faculty development activities. He teaches graduate courses in research methods and educational development at the Ontario Institute for Studies in Education/ U. of Toronto.

Ron Smith is a professor of Adult Education at Concordia University in Montreal and was the Director of their Centre for Teaching and Learning Services for 23 years. He is a former President of POD and a 3M Teaching Fellow. His current research interests are in the professionalization of professional development and in the application of "reflective practice" to improving teaching in higher education.

Zohar Waisman is a resident in Psychiatry at the University of Toronto who conducts research on psychiatric education. 


\section{FIGURE 1 \\ Building a Definition of Expertise*}

\begin{tabular}{|l|}
\multicolumn{1}{|c|}{ Bereiter and } \\
Scardamalia's View \\
Expertise as \\
investment and \\
progressive problem- \\
solving and a \\
willingness to tackle \\
challenging \\
problems that \\
increase expertise \\
(Bereiter \& \\
Scardamalia, 1993)
\end{tabular}

Traditional View from Cognitive Science

Expertise as a way of solving problems efficiently by making use of patterns and learned procedures

(Dreyfus \& Dreyfus, 1986; Anderson, 1985; Salthouse, 1991)

\section{Common Sense View}

Expertise as knowledge-everyone is an expert at something, but society normally reserves the term for those learners whose knowledge is distinguished as particularly valuable.

*C 1998, Richard Tiberius, Ronald Smith and Zohar Waisman 